\title{
A blended learning Grade 12 intervention using DVD technology to enhance the teaching and learning of mathematics
}

\author{
Authors: \\ Pragashni Padayachee ${ }^{1}$ \\ Hennie Boshoff ${ }^{1}$ \\ Werner Olivier ${ }^{1}$ \\ Ansie Harding ${ }^{2}$ \\ Affiliations: \\ ${ }^{1}$ Department of Mathematics \\ and Applied Mathematics, \\ Nelson Mandela \\ Metropolitan University, \\ South Africa \\ ${ }^{2}$ Department of \\ Mathematics, University of \\ Pretoria, South Africa \\ Correspondence to: \\ Pragashni Padayachee \\ Email: \\ pragashni.padayachee@ \\ nmmu.ac.za \\ Postal address: \\ Department of Mathematics \\ and Applied Mathematics, \\ Nelson Mandela \\ Metropolitan University \\ (South Campus), Port \\ Elizabeth 7000, South Africa \\ Dates: \\ Received: 08 Feb. 2010 \\ Accepted: 08 July 2011 \\ Published: 13 Sept. 2011 \\ How to cite this article: \\ Padayachee, P., Boshoff, H., \\ Olivier, W., \& Harding, A. \\ (2011). A blended learning \\ Grade 12 intervention using \\ DVD technology to enhance \\ the teaching and learning of \\ mathematics. Pythagoras, \\ 32(1), Art. \#24, 8 pages. \\ http://dx.doi.org/10.4102/ \\ pythagoras.v32i1.24
}

(C) 2011. The Authors. Licensee: AOSIS OpenJournals. This work is licensed under the Creative Commons Attribution License.
This article describes the experiences and mathematics performance of Grade 12 learners selected to participate in a mathematics intervention project using digital video disk (DVD) technology within a blended learning context. Blended learning in the context of this study is defined as employing a variety of appropriate methods of delivery to enhance the teaching and learning process. DVD technology was used as an ingredient in this blended learning approach, since it is easily available and accessible to the majority of learners and the schools they attend. The study reported on here forms part of a larger study using action research methodology. This article reports on a single stage of the action research: implementing a change to improve the situation and observing the consequences of this action. Mathematics Incubator School Project (ISP) learners completed questionnaires with open-ended questions which pertained to their experiences of the blended learning approach. The observations of the facilitators were also recorded. A single school was used as a case study and the mathematics performance of learners who participated in the ISP was compared with that of those who did not. The findings suggest that use of DVD technology in this blended learning approach impacted on mathematics learning and enhanced the mathematics performance of learners.

\section{Introduction}

The ongoing poor quality in mathematics teaching and learning in South Africa is the 'most important obstacle to African advancement' (Centre for Development and Enterprise, 2004, p. 239). At the heart of this concern is the fact that the present education system has disadvantaged learners by failing to meet their educational needs, especially regarding mathematics (Evoh, 2009). It has been our observation in lecturing first-year mathematics students at a large metropolitan university in the Eastern Cape in South Africa that many first-year students are under-prepared for mathematics. This under-preparation may be attributed to the shortage of adequately qualified teachers and lack of resources at schools attended by the majority of learners (Adler, Brombacher \& Human, 2000).

Many interventions in response to this crisis in the teaching and learning of mathematics are documented in the literature. There are interventions which specifically target the learner, such as the PetroSA Maths and Science Academy in Mossel Bay (Government Communication and Information System, 2008), Schools of Excellence Project (Zenex Foundation, 2007), and national Dinaledi schools (Department of Education, 2004), whose aim it is to improve learners' achievements in mathematics and science. There are interventions where the aim is to uplift the skills of the teacher, like the Ergo programme (AngloGold Ashanti, 2009). However, none of these secondary school mathematics interventions make use of technology in the teaching and learning of mathematics within a blended learning approach.

In this technologically advanced era it would seem natural to question whether 'relatively accessible and affordable technologies' can contribute towards addressing the poor quality of teaching and learning (Nieuwoudt, Nieuwoudt \& Monteith, 2007, p. 29). Moreover, as technology becomes more advanced and easily accessible there is a shift from traditional, teacher-centred classroom instruction to a more learner-centred approach to teaching and learning (Cohen, Grady \& Springer, 2003). The traditional teacher-centred approach is inappropriate to outcomesbased education with its central focus on learner-centredness (Badenhorst \& De Beer, 2004). However, technology alone will not create the ideal learning environment (Luca, 2006). This idea is supported by Singh and Reed (2001), who cite research from Stanford University and the University of Tennessee when they suggest that blended learning is better than either traditional methods or the use of technology alone.

Blended learning incorporates different modes of delivery to enhance the learning experience and provide a more efficient and effective teaching experience. Singh and Reed (2001) suggest 
that in developing an efficient and effective blended learning model, consideration should be given to the achievement of learning outcomes when using the 'right technology' to match the learning styles of the learner. Therefore blended learning involves use of an appropriate mix of delivery techniques and technologies to enrich the learning experience and achieve the outcomes of this learning (Maguire \& Zhang, 2006).

A need was identified for an intervention in the teaching and learning of mathematics in South Africa that uses technology together with a variety of other delivery modes. The blended approach incorporating digital video disk (DVD) technology which is described in this article presents a financially feasible opportunity in the teaching and learning of mathematics to improve mathematics results of a Grade 12 intervention group. The rationale behind this approach is that although the learners on this project did not have access to Internet, they all had access to a DVD player. Ideally the DVDs should be used in a blended learning environment with the additional inputs of facilitators. However, the DVDs are designed to be used as an independent learning resource as well. The fixed mathematics content of the DVD ensures that mathematical concepts are not watered down or misrepresented during presentations. This was particularly helpful to learners during the 2007 teachers' strike, which impacted the mathematics learning of many of the learners.

In this article a blended approach to teaching and learning mathematics is evaluated, with the focus on how learners experienced this approach and whether it impacted on their mathematical performance. The guiding research question for this research is: How can a blended learning approach that incorporates DVD technology contribute to improving the quality of teaching and learning in secondary school mathematics?

\section{The context}

The Mathematics Incubator School Project (ISP) was initiated in 2004. The aim of the ISP is to address the serious shortage of suitably qualified mathematics secondary school teachers and the shortage of students from Eastern Cape schools entering into higher education in the fields of science, mathematics and technology.

The ISP teaching and learning approach has undergone many changes over the past 4 years:

- in 2004 traditional classroom teaching (no fixed lesson plans) was used

- in 2005 traditional classroom teaching (fixed lesson plans) was used

- in 2006 PowerPoint slide presentations of topics were used during lessons

- in 2007 a series of 20 DVDs covering mathematics topics necessary for the then Grade 12 mathematics curriculum was developed and used within the blended learning approach.
The focus of the 2007 ISP was to develop innovative, new, learner-centred learning programmes and strategies using appropriate technologies to facilitate the effective teaching and learning of mathematics.

\section{The blended learning DVD approach used in the 2007 ISP}

A blended learning approach was adopted in these ISP deliveries. Graham (2004, p. 8) says that a 'more effective pedagogy' is one of the reasons for blended learning, since blended learning aims to create an environment that allows a shift to more learner-centredness. The challenge is to blend the right resources and activities to optimally enhance the learning experience. Singh and Reed (2001) highlight the following as key ingredients of a blended programme:

- cognizance of the level of knowledge that the learners bring to the programme, different and shared learning styles of the learners, their motivation levels and ability to access technology

- content analysis to determine selection of appropriate delivery modes

- financial implications of delivery

- infrastructure to support the use of technology.

The aforementioned ingredients were considered in the design of the 2007 ISP. Learners' levels of mathematics knowledge were based on their Grade 11 mathematics results. However, learners attended different high schools and did not write a uniform mathematics examination. It became clear after the 2007 ISP implementation that a pre-test should be administered in order to determine the mathematics knowledge of learners.

The skills-driven learning model (Valiathan, 2002) was used in the ISP deliveries; this combines self-paced learning with instructor or facilitator support to develop specific knowledge and skills. Valiathan (2002) expounds further that in this type of approach, interaction with the facilitator acts as a catalyst to achieve learning and keeps the learner from experiencing feelings of isolation. There are many possibilities which constitute a blended learning approach. In particular, live face-to-face: formal (facilitator-led classroom), live faceto-face: informal (mentoring by tutors and collaborative learning with peers) and self-paced learning (DVDs) were used in all ISP deliveries (Rossett, Douglis \& Frazee, 2003).

In the blended learning environment reported on here, the use of easily accessible and affordable DVDs was decided upon since the learners did not have Internet access and broadband facilities to enable online learning or facilitate video streaming. Also, many learners did not have computer skills, and were therefore not disadvantaged by this approach.

The term blended learning here meant that each DVD covering a particular concept in the Grade 12 mathematics syllabus was designed for viewing in a short session. This allowed for facilitator discussion, tutor interaction, peer 
interaction and also working on assigned tutorial problems during contact sessions, which were conducted on Saturdays. Once the learning outcomes were completed for a particular section, the DVD presentation was resumed, and so the cycle continued. Learners were given hard copies of all the tutorials as well as solutions to the tutorial problems. Each learner was also given a personal copy of the DVD to view at their own pace at home. Learners were assessed on the concepts covered on a particular DVD upon their return the following Saturday. Table 1 represents a list of blends used in the ISP deliveries.

A schematic model of the blended learning approach is shown in Figure 1.

\section{Instructional design of the DVDs}

Each DVD covered a particular topic in the syllabus; the topic was then divided into micro lessons (parts). Each part of a DVD topic started with an introduction and definitions of the concepts, and this was followed by fully explained examples pertaining to that particular concept. The intention was to give learners an understanding of the thought processes involved in solving a problem and to help learners who would have no idea where to begin (Aminifar, Porter, Caladine \& Nelson, 2007). The part ended with tutorial problems to be attempted by the learners, intended to give them a way to assess their understanding of the micro lesson. A set of comprehensive solutions followed, that could be viewed after learners had attempted the tutorial problems. This approach ensured that immediate feedback was available to any learner who struggled with the tutorial problems. The entire DVD had voice narration integrated with animated PowerPoint slides. Table 2 shows the content topics covered in the 2007 mathematics DVD series.

\section{Production of the DVDs}

PowerPoint slides with animation were developed for each mathematical concept and formed the basis of the recording of the DVDs. Recordings were done in a studio by a member of the ISP team, normally a lecturer in the Mathematics and Applied Mathematics Department at the university in question. Recordings entailed using a tablet PC and presenting the PowerPoint slides with voice explanations. Other software packages like Autograph were used to illustrate sections requiring graphic drawing. Whilst recordings were being done, a second academic staff member evaluated them to ensure that the DVDs were free of mathematical errors. Re-recording of an erroneous slide took place immediately if necessary. Thereafter a technical media specialist edited the DVDs to produce master DVDs with a menu-driven system.

\section{The Saturday programme}

Learners attended a series of five-hour sessions held on Saturdays, during which two DVDs of one hour each were facilitated. After each session, learners engaged with tutorial problems. This was an interactive session, with discussions and assistance from facilitators as well as student tutors.
TABLE 1: List of blends.

\begin{tabular}{ll}
\hline Blends & Activity \\
\hline Facilitation & $\begin{array}{l}\text { Two mathematics lecturers and one high school teacher took the } \\
\text { roles of facilitators during these deliveries. }\end{array}$ \\
$\begin{array}{l}\text { DVD viewing } \\
\text { Discussions }\end{array}$ & $\begin{array}{l}\text { Two DVDs were presented per Saturday session. } \\
\text { Tutorials }\end{array}$ \\
\hline
\end{tabular}

Source: Padayachee, P. (2011). A case study: Exploring a DVD driven approach for teaching and learning mathematics, at secondary school level, with a framework of blended learning. Unpublished doctoral dissertation. Nelson Mandela Metropolitan University, Port Elizabeth, South Africa. Available from http://www.nmmu.ac.za/documents/theses/Pragashni\%20 Padayachee.pdf

DVD, Digital video disk.

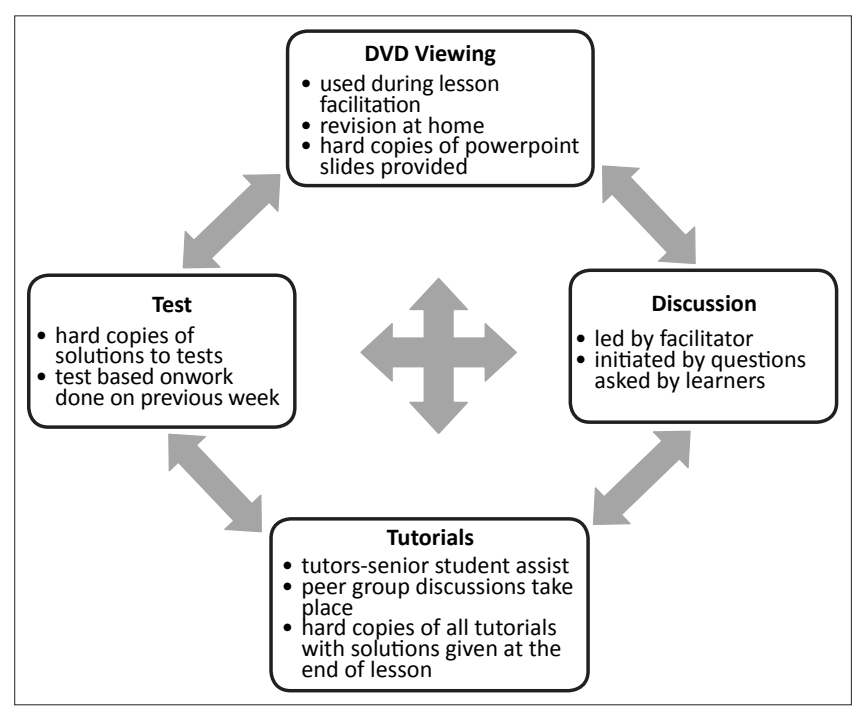

Source: Padayachee, P. (2011). A case study: Exploring a DVD driven approach for teaching and learning mathematics, at secondary school level, with a framework of blended learning. Unpublished doctoral dissertation. Nelson Mandela Metropolitan University, Port Elizabeth South Africa. Available from http://www.nmmu.ac.za/documents/theses/Pragashni\%20 Padayachee.pdf

FIGURE 1: The 2007 blended learning approach.

TABLE 2: The 20 mathematics DVD topics.

\begin{tabular}{ll}
\hline DVD No. & Topics \\
\hline DVD 1 & Basic Algebra \\
DVD 2 & Remainder and Factor Theorem \\
DVD 3 & Quadratic Equations, Nature of Roots \\
DVD 4 & Solving Non-linear Inequalities \\
DVD 5 & Basic Graphs \\
DVD 6 & Applications of Graphs \\
DVD 7 & Indices, Logarithms and Surds \\
DVD 8 & Absolute Value and Linear Inequalities \\
DVD 9 & Analytical Geometry I \\
DVD 10 & Analytical Geometry II \\
DVD 11 & Introduction to Differential Calculus \\
DVD 12 & Applications of Differential Calculus \\
DVD 13 & Solving Exponential and Logarithmic equations \\
\hline DVD 14 & Trigonometric: Compound Angles \\
DVD 15 & Trigonometric Equations \\
DVD 16 & Trigonometric Graphs \\
DVD 17 & Geometry: Proportion \\
\hline DVD 18 & Geometry: Similarity \\
DVD 19 & Arithmetic Sequences and Series \\
DVD 20 & Geometric Sequences and Series \\
\hline DVD Dgita &
\end{tabular}

DVD, Digital video disk.

The DVDs were presented to learners using a DVD player connected to a data projector. 


\section{Research design Research method}

The research reported on in this article is part of a larger research study investigating the teaching and learning of mathematics using DVD technology within the context of blended learning. The focus of this research study was the 2007 ISP which forms part of a larger project. The 2002-2006 ISP were earlier cycles of this larger action research project. The evaluation of each cycle in this action research informed the next cycle in the project (e.g. Boshoff \& Olivier, 2008). In 2007 the use of DVD technology was introduced in the ISP, and this article focuses on use of DVD technology within a blended learning environment in the 2007 ISP.

\section{Participants}

A total of 184 Grade 12 mathematics learners from local schools in the Nelson Mandela Metropole were selected to participate in the 2007 ISP. The best-performing learners were selected on the basis of their Grade 11 mathematics marks and their interest in pursuing studies in Science, Engineering, Technology and Mathematics and Science Education. These learners were split into four groups, with on average 46 learners to one facilitator in each group. These learners and their facilitators were the participants in this research study.

\section{Action research}

Action research is the methodology used in the larger research study, and this study focuses on one aspect of the action research cycle. Action research provides an important link between research and teaching, particularly when the research is actively conducted with the aim of informing teaching and learning and challenging ways of incorporating technology into the curriculum (Manchester, Ralph \& Shipova, 2005). Action research was an appropriate design in the larger research study in order to reflect on the processes that were followed and to refine the ISP before the next cycle of implementation. The following steps in the action research cycle were followed in the larger study: plan and design the intervention; implement the intervention; evaluate the intervention; reflect on the evaluation; and implement the changes - and so begins another cycle.

This article focuses on the third phase in the action research cycle, namely the evaluation of the ISP intervention, and in so doing concentrates on factors that contributed to a supportive and encouraging learning environment. In particular, the focus was on the experiences of learners and the impact of the blended learning approach on their mathematical ability.

During the evaluation phase of the action research cycle a mixed-methods approach to collecting data was adopted, with both qualitative and quantitative methods employed. At the end of the 2007 programme 184 learners completed a questionnaire aimed at evaluating the teaching and learning approach they had experienced. The questionnaire contained open-ended questions and provided rich descriptive data with regard to the factors that provided a supportive and encouraging learning environment. Further to this, qualitative data were also collected in the form of facilitator observation of the learning process using weekly reports. Using quantitative methods, the learners' final Grade 11 mathematics results were compared with their final Grade 12 mathematics results to determine whether an improvement in mathematical performance had occurred as a result of this blended learning intervention.

The case study of a single school of 20 learners, 6 of whom were ISP participants and 14 non-ISP participants, is also described here. There was difficulty in obtaining the results of other learners at schools that participated in the 2007 ISP.

\section{Validity and reliability}

Use of various methods of data collection and triangulation were vital in determination of an in-depth understanding of the programme under investigation. Strategies for promoting validity and reliability (adapted from Merriam, 2002, p. 31) used in this research study are outlined in the following section.

- Triangulation: The researchers used multiple sources of data and data collection methods to confirm emerging findings. Triangulation was as follows:

- Data triangulation: Questionnaires completed by learners and reports completed by facilitators.

- Methodological triangulation: Use of qualitative and quantitative methods.

- Member checks: The researchers took the tentative interpretations of the data back to the learners and facilitators to see if they agreed with them.

- Peer review: The process of the research study, congruency of emerging findings with the raw data and tentative interpretations were discussed with colleagues.

- Researchers' position: The researchers undertook critical self-reflection with regard to their worldview, assumptions and relationship to this study that could have influenced bias and affected this study.

- Adequate engagement in data collection: It was ensured that adequate data were collected such that the data became saturated.

- Rich, thick descriptions: The researchers tried to supply sufficient descriptions to enable readers to determine whether this situation matches their research context or whether the findings can be transferred.

\section{Ethical considerations}

Denscombe (2007, p. 142) outlines three core principles that should inform the ethical choices and guide the activities of the researcher. The principles as applied in this research study were as follows:

Principle 1: The interest of the participants should be protected. This research ensured the confidentiality of the participants. Data were kept safe and no personal identities were revealed in disclosure of the results. 
Principle 2: Researchers should avoid deception or misrepresentation. The researchers were honest and made all the processes transparent. The researchers and participants developed a relationship of trust, and the researchers presented the data in a fair and unbiased way.

Principle 3: The participants should give informed consent. Ethical clearance was given by the Research Committee of the university where the ISP is based. The Department of Education gave its consent for the researchers to access participants from schools in the Eastern Cape. Written consent was obtained from all the participants and in the case of minors consent was received from their parents. All participation was voluntary.

\section{Results and discussion}

Analysis of the questionnaires, facilitator reports, comparisons of learners' Grade 11 and Grade 12 mathematics marks and the case study are presented and discussed.

In analysis of the data collected from learners' questionnaires and facilitators' weekly reports, the themes outlined below arose.

\section{Themes which arose from the data New experience}

More than half of the learners felt that the approach was refreshing and a different way of learning mathematics. Many learners said they found this way of learning enjoyable and exciting. A few learners said that the DVD was different from a textbook, since there was a 'voice' explaining the concepts.

\section{DVD as a resource}

Learners felt that explanations of the mathematical concepts were good and the concepts were presented well. The DVD was particularly useful to them in sections that required visual representation (drawing graphs) and in Calculus, since it was 'not done well' at school. Many learners said they found the DVDs helpful and that they found the mathematics easy to understand because of the many examples and illustrations on the DVDs.

A few learners said that they found it easier to concentrate using this method as opposed to having someone standing in front explaining what to do. On the other hand, a few other learners found it difficult to concentrate using the DVD approach, and one said it was easy to 'move your concentration elsewhere' unless you had a lecturer to intervene with discussion or explanations.

Many learners said the DVD approach gave more insight than school, and that they found it helpful to do a section on DVD in the Saturday project before it was done at school, and that this helped their understanding of the section. Learners also used the DVD to 'test and check' their understanding of a particular concept. They found that the DVD series was a good resource to consult when faced with homework or in preparation for a test or examinations. Many learners said that the DVDs allowed them to learn at their own pace and to watch a section over again until they understood the concepts. Many found that they could watch the DVDs at home and revise together with the resource material; this approach helped to enhance their understanding.

However, some learners suggested that some of the DVDs did not illustrate every step of a mathematical problem, which led to confusion. They asked for more detail and more examples on the DVDs.

\section{The blended learning environment}

Although most of the learners agreed that the DVD was a useful resource, many said they needed facilitators and tutors for further explanations and discussions. They needed the facilitators' explanations to bridge gaps where the DVD skipped steps or where they had problems understanding. According to the learners, tutors, facilitators and discussions with other learners helped them see concepts from different viewpoints.

Learners felt that their English improved as a result of the blended learning approach, although one learner suggested that DVDs be produced in other languages. Learners said that they liked the way the ISP presentations blended the tutorials, DVDs and discussions, and that this made it easier for them to concentrate for longer periods.

The issue that stands out and which was pointed out by almost all learners was the ease with which learners could view the DVD and replay and pause whenever they wanted to. However, some learners mentioned that whilst watching the DVD there were questions that needed explanation, and that the DVD should not be used alone. A few learners also said that their teacher used these DVDs at their schools to teach certain topics, like Calculus, for example. Some learners formed study groups and watched the DVDs in these groups over weekends.

The blended learning approach using DVDs presented a new way of learning mathematics to or for the learners, and most of them were positive that the method benefited their understanding of the subject. The approach allowed them the freedom to access a variety of different resources, and allowed them to work at their own pace and to revise at home.

\section{Facilitators' observations}

The facilitators' observations of learners' experiences of the blended learning environment were positive and encouraging. All four facilitators felt that the learners' confidence improved as a result of this approach. In addition, one facilitator noted that as the project progressed, communication and engagement with the facilitators and learners, tutors and learners, and amongst the learners improved. A facilitator said that the level of mathematics 
questions posed by the learners improved with time, and the learners' test performances improved steadily as the project progressed. All the facilitators agreed that the interaction in the blended learning approach was lively, although learners found it (i.e. DVD technology) strange at first.

One facilitator said that the 'DVD is a powerful resource allowing learners to work at their own pace and review solutions and procedures until they understood the concept'. All four facilitators said that they believed that DVDs should be used in conjunction with other face-to-face methods of teaching and learning. They believed that used in isolation, the DVDs would not prove such a successful resource in the teaching and learning of mathematics.

Evidence is provided which suggests that DVD technology impacted on the mathematics learning and enhanced the mathematics performance of the ISP learners. In addition, the learners responded favourably to use of the DVD technology within the blended learning environment. However, some learners said that at first they needed to adjust to this new learning environment. They also indicated that once they had adjusted, they could see the advantages of being exposed to different modes of delivery.

The majority of the learners agreed that this blended environment of teaching and learning mathematics fostered a deeper understanding of the subject for them. The most important point raised by learners was the fact that DVDs alone were not sufficient to ensure success. They believed that the DVDs together with facilitators' and tutors' explanations and discussion coupled with the hard copy resources were the best blended approach for their learning of mathematics.

\section{Improvement in marks}

Statistical analysis was undertaken to investigate whether differences between the final Grade 11 mathematics marks and final Grade 12 mathematics marks of the ISP learners were significant. The descriptive statistics comparing the final Grade 11 marks with the final Grade 12 marks are shown in Table 3.

The observed difference of 2.96 between the mean scores shows a statistical significance; however, no practical significance is noted.

Figure 2 illustrates that the distribution for Grade 11 marks peaks with the majority of scores between 40 and 59, whereas the distribution for Grade 12 is evenly spread, having moved from the middle to the other categories. The KolmogrovSmirnov Test $(\mathrm{K}-\mathrm{S} \mathrm{D}=0.245, p<0.01)$ confirms a significant difference in distribution.

It is pleasing to note that in higher intervals from 60 upwards there is clearly an improvement of marks from Grade 11 to Grade 12 . In the category of $70+$ there is an increase from Grade 11 to Grade 12, from 4\% to $22 \%$. Unfortunately, there also are more students who performed badly in Grade 12 compared to Grade 11: there is an increase in the under- 40
TABLE 3: Descriptive statistics for Grade 11 and Grade 12 mathematics marks $(N=184)$.

\begin{tabular}{lccc}
\hline Statistics & Grade 11 & Grade 12 & Difference \\
\hline Mean & 48.41 & 51.36 & $2.96^{*}$ \\
SD & 9.97 & 18.21 & 17.03 \\
Minimum & 23.00 & 9.00 & -44.00 \\
Quartile 1 & 41.00 & 39.00 & -8.25 \\
Median & 48.00 & 50.00 & 2.00 \\
Quartile 3 & 53.00 & 68.00 & 15.25 \\
Maximum & 86.00 & 90.00 & 50.00 \\
\hline
\end{tabular}

$N$, Total number of learners; SD, Standard deviation.

$t=2.35 ; d f=183 ; d=0.17$

$*, p=0.020$

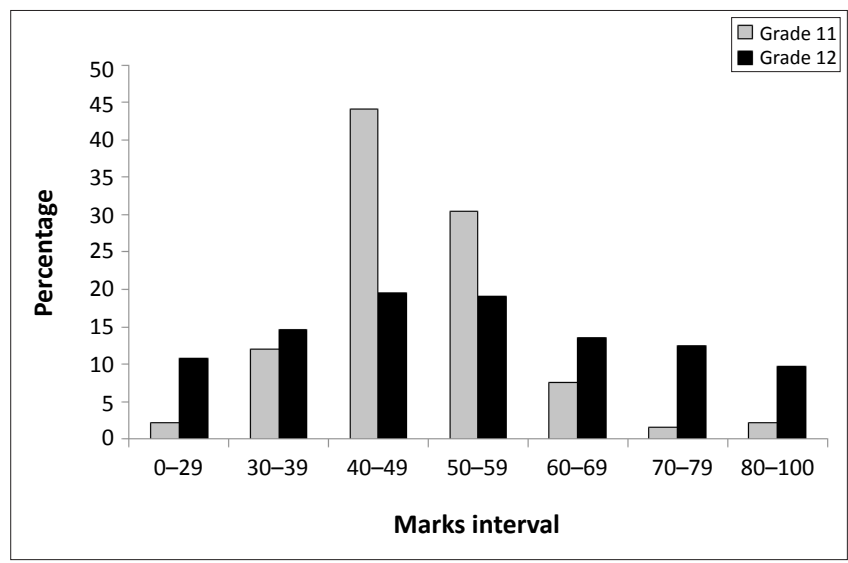

FIGURE 2: Distribution of Grade 11 and Grade 12 mathematics marks.

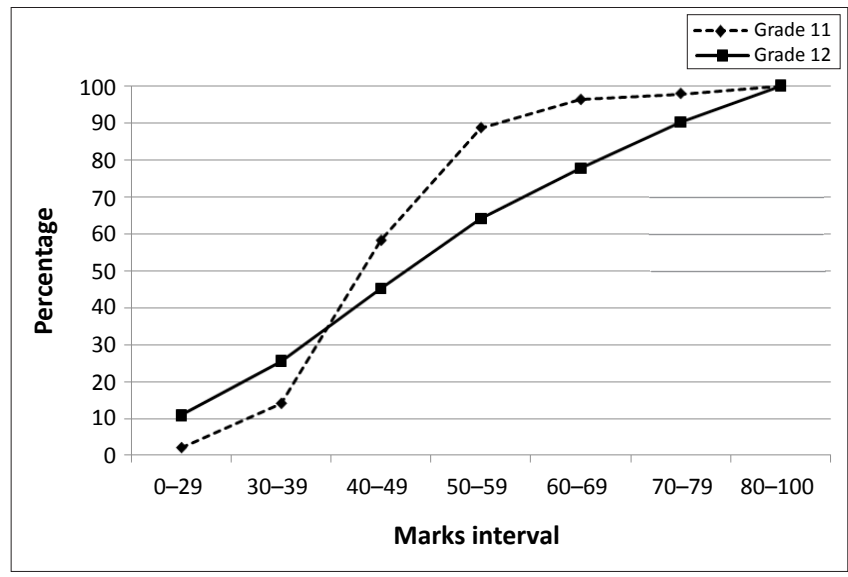

FIGURE 3: Cumulative distribution of Grade 11 and Grade 12 mathematics marks.

intervals; in fact, there is an increase in the interval 0-39, from $14 \%$ in Grade 11 to $26 \%$ in Grade 12.

Figure 3 confirms that the distribution for Grade 11 is flatter, with more results between 40 and 69 , whereas the distribution for Grade 12 is more evenly spread.

Table 4 and Figure 3 reflect the difference in distribution between Grade 11 and Grade 12. The relationship between the categories of marks for Grade 11 and Grade 12 is depicted in Table 4.

It is interesting to note that no learners from the $0-39$ category in Grade 11 moved to the 70+ category in Grade 12, and none of the learners in the category 70 in Grade 11 moved to the $0-39$ category in Grade 12 . It is also noteworthy that $25 \%$ of 
TABLE 4: Contingency table of Grade 11 and Grade 12 mathematics marks.

\begin{tabular}{|c|c|c|c|c|c|c|c|c|}
\hline \multirow[t]{3}{*}{ Grade 11 marks } & \multicolumn{8}{|c|}{ Grade 12 marks } \\
\hline & \multicolumn{2}{|c|}{$0-39$} & \multicolumn{2}{|c|}{$40-69$} & \multicolumn{2}{|c|}{$70+$} & \multicolumn{2}{|c|}{ Total } \\
\hline & $N$ & $\%$ & $N$ & $\%$ & $N$ & $\%$ & $N$ & $\%$ \\
\hline $0-39$ & 18 & 69 & 8 & 31 & 0 & 0 & 26 & 100 \\
\hline $40-69$ & 29 & 19 & 85 & 56 & 37 & 25 & 151 & 100 \\
\hline $70+$ & 0 & 0 & 3 & 43 & 4 & 57 & 7 & 100 \\
\hline Total & 47 & 26 & 96 & 52 & 41 & 22 & 184 & 100 \\
\hline
\end{tabular}

$N$, Total number of learners.

TABLE 5: Case study - Grade 11 and Grade 12 end-of-year marks for mathematics.

\begin{tabular}{|c|c|c|c|c|c|c|c|c|c|c|c|c|c|c|c|c|c|c|c|c|}
\hline \multirow[t]{3}{*}{$\overline{Y e a r}$} & \multicolumn{20}{|c|}{ Participants end-of-year marks for mathematics } \\
\hline & \multicolumn{6}{|c|}{ ISP Learners } & \multicolumn{14}{|c|}{ Non-ISP Learners } \\
\hline & 1 & 2 & 3 & 4 & 5 & 6 & 7 & 8 & 9 & 10 & 11 & 12 & 13 & 14 & 15 & 16 & 17 & 18 & 19 & 20 \\
\hline 2006 & 46 & 47 & 46 & 51 & 52 & 40 & 28 & 34 & 35 & 44 & 37 & 32 & 47 & 39 & 42 & 37 & 44 & 42 & 43 & 39 \\
\hline 2007 & 80 & 60 & 60 & 60 & 70 & 70 & 10 & 10 & 10 & 40 & 10 & 10 & 40 & 10 & 42 & 10 & 10 & 40 & 40 & Absent \\
\hline
\end{tabular}

ISP, Incubator School Project; Non-ISP, Non-Incubator School Project.

the learners in the 40-49 category in Grade 11 moved to the $70+$ category in Grade 12.

The quantitative data indicated statistical significance, and it seems that there was an improvement from the Grade 11 to the Grade 12 mathematics marks in many cases. However, it became clear from the quantitative data that not all learners responded positively to the blended learning approach.

\section{Case study}

A school in the Uitenhage district was used as a case study. There were 20 learners in this Grade 12 mathematics class. Six of these learners participated in the 2007 ISP. For all 20 learners, their 2007 final Grade 12 mathematics marks were compared with their 2006 Grade 11 end-of-year mathematics marks. Results of the learners who were on the ISP improved, whilst those learners not on the ISP generally presented lower Grade 12 final results.

To determine whether the difference was statistically significant, a Mann-Whitney U Test $(z=3.38, p=0.001$, $d=3.20$ ) was conducted. A Cohen's D test was conducted for practical significance. It was found that the difference in means was highly significant, since $d>0.8$ reflects a large difference. The results are summarised in Table 5 and Table 6.

\section{Conclusion}

The research question addressed in this article was how can a blended learning approach that incorporates DVD technology contribute to improving the quality of teaching and learning in secondary school mathematics?' From the study it is clear that this blended approach offers a workable teaching approach with definite advantages. One of the advantages of using DVD technology within a blended approach is accessibility of the subject content and presentation outside the classroom.

Qualitative results indicated that both learners' and teachers' experiences were largely positive, with concerns identified that offer opportunity for improvement. Most learners attributed their better understanding of mathematical concepts taught to the DVD approach that was used in conjunction with other traditional modes of delivery.

Quantitative results indicated statistical significance when comparing the mean scores for Grade 11 and Grade 12 results, although not of practical value. According to Calldo and $\mathrm{Du}$ Plooy (2008), the percentage of students passing mathematics on higher grade declined from $7.2 \%$ in 2006 to $6.9 \%$ in 2007 . In the face of declining performance in mathematics in South Africa in the 2007 matriculation examination, our results seem to suggest that the DVD approach of blended learning could in some way have contributed to the improvement in mathematics results that was noted amongst many of the ISP learners, especially the better students. It is disappointing that a large group of the borderline students did not seem to benefit from this blended learning approach. This finding is reason for concern, since these are the students that should be targeted - and the reason for this disappointing deterioration has to be investigated.

The fact that the DVD technology is easily accessible and affordable supports a case that the DVD approach could also help to address the shortage of adequately qualified teachers and lack of teaching resources at previously disadvantaged schools in South Africa.

Harding, Kaczynski and Wood (2005) say that in order to be successful in using blended learning, one has to not only implement learning reforms but also, importantly, evaluate these reforms, and in so doing provide students with the best possible outcomes. The ISP saw the implementation

TABLE 6: Case study - Difference in means of Grade 11 and Grade 12 end-ofyear marks for mathematics.

\begin{tabular}{lcc}
\hline Difference in means & \multicolumn{2}{c}{ Participants } \\
\cline { 2 - 3 } & ISP & Non-ISP \\
\hline 2006 mean & 47.00 & 38.79 \\
2007 mean & 66.67 & 21.69 \\
Difference between 2007 (Grade 12) mean & & \\
and 2006 (Grade 11) mean & 19.67 & -17.08 \\
Standard deviation difference & 10.05 & 12.08 \\
\hline
\end{tabular}

ISP, Incubator School Project; Non-ISP, Non-Incubator School Project. 
of DVD technology for the first time in 2007, and this research aimed to evaluate its value to the teaching and learning of mathematics. In order to provide learners with the best possible outcomes, 'it is important that we continue to identify successful approaches of blended learning at institutional, programme, course and activity levels that can be adapted to work in contexts' (Graham, 2004, p. 19).

Our DVD blended learning approach still requires further development and refinement, especially with regard to the skills of facilitators within such a blended learning environment and the development of materials. These and other issues will be looked at in future research initiatives.

\section{Acknowledgements}

We are grateful to SASOL for the funding that supported the 2007 ISP and this research.

\section{Competing interests}

We declare that we have no financial or personal relationships which may have inappropriately influenced us in writing this article.

\section{Authors' contributions}

H.B. was the project leader whilst H.B. and W.O. were responsible for the project design. H.B. collected the data. A.H. made conceptual contributions. P.P. performed the qualitative and statistical analysis, made conceptual contributions and wrote the manuscript. H.B., W.O. and A.H. reviewed the drafts of this research article.

\section{References}

Adler, J., Brombacher, A., \& Human, P. (2000). Submission by the mathematics education community to the Council of Education Ministers. Retrieved July 20 2011, from http://www.sun.ac.za/mathed/AMESA/NGO.htm

Aminifar, E., Porter, A., Caladine, R., \& Nelson, M.I. (2007). Creating mathematical learning resources - Combining audio and visual components. Anziam Journal, 47, C934-C955. Available from http://anziamj.austms.org.au/ojs/index.php/ ANZIAMJ/article/view/1083

AngloGold Ashanti. (2004). Report to society. Retrieved August 12, 2009, from http:// www.anglogold.com/subwebs/informationforinvestors/ReportToSociety06/AGAFund.htm

Badenhorst, J.J.C., \& De Beer, K.J. (2004, June-July). Blended learning at the Central University of Technology, Free State. Paper presented at the Emerge 2004 Online Conference. Available at http://emerge2004.net/connect/site/UploadWSC/ emerge2004/file20/emerge2004article.doc
Boshoff, H., \& Olivier, W. (2008). Impact of DVD technology on improving the mathematical performance of learners. In H.H. Boshoff, V.G. Govender, \& L. Heymans (Eds.), Proceedings of the 14th Annual Congress of the Association for Mathematics Education of South Africa, Vol. 1 (pp. 29-40). Port Elizabeth: Association for Mathematics Education of South Africa. Available from http:// www.amesa.org.za/amesa2008/volume1.pdf

Government Communication and Information System. (2008). PetroSA opens maths, science academy. Buanews Online, 28 October 2008. Retrieved August 26, 2009, from http://www.buanews.gov.za/news/08/08102816151001

Calldo, F., \& du Plooy, T. (2008). Eskom: "Skills Facts". Retrieved October 20, 2009 from http://www.solidariteitinstituut.co.za/docs/skills_fact.pdf

Centre for Development and Enterprise. (2004). From laggard to world class: Reforming maths and science education in South Africa's schools. Johannesburg: Centre for Development and Enterprise. Available at http://www.cde.org.za/ attachment view.php?aa id $=208$

Cohen M.L., Grady, M., \& Springer, S. (2003). Centering on Learning at Penn. University of Pennsy/vania Almanac, 50(9). Available from http://www.upenn.edu/almanac/ v50/n09/teaching.html

Denscombe, M. (2007). The good research quide for small-scale social research projects. Maidenhead: Open University Press.

Department of Education. (2004). Dinaledi project: National strategy for Mathematics, Science and Technology education. Department Briefing to Parliamentary Education Portfolio Committee, 26 October 2004. Retrieved August 12, 2008, from http://www.pmg.org.za/node/4759

Evoh, J.C. (2009). The role of social entrepreneurs in deploying ICTs for youth and community development in South Africa. Journal of Community Informatics, 5(1) Available from http://ci-journal.net/index.php/ciej/article/view/459/438

Graham, C.R. (2004). Blended Learning Systems. In C.J. Bonk, \& C.R. Graham (Eds.), Handbook of blended learning: Global perspectives, local designs (pp. 3-21). San Francisco: Pfeiffer Publishing.

Harding, A., Kaczynski, D., \& Wood, L. (2005). Evaluation of blended learning: Analysis of qualitative data. In Proceedings of the UniServe Science Blended Learning Symposium, 30 September 2005 (pp. 56-61). Sydney, Australia: The University of Sydney. Available from http://wenku.baidu.com/view/ bd377819ffoobed5b9f31dea.html

Luca, J. (2006). Using blended learning to enhance teaching and learning. In D. Tolhurst, \& S. Mann (Eds.), Proceedings of the 8th Australian Conference on Computing Education, 16-19 January 2006, Vol. 52 (pp. 3-4). Darlinghurst, Australia: Australian Computer Society.

Maguire, C., \& Zhang, J. (2006). Effective blended learning for development. Compilation of materials for workshop on designing and delivering blended distance learning programs through GDLN, sponsored by World Bank Tokyo Development Learning Center and DGHE Indonesia. Jakarta, November 2006.

Manchester, H., Ralph, S., \& Shipova, O. (2005). The teacher's role in using WebCT as a communication tool with postgraduate students. The International Journal of Learning, 12(4), 101-107.

Merriam, S.B. (1998). Case study research in education: A qualitative approach. San Francisco: Jossey-Bass Publishers.

Nieuwoudt, S., Nieuwoudt, H., \& Monteith, J. (2007). Influence of a video class system on learners' study and learning strategies and their achievement in mathematics. African Journal of Research in Mathematics, Science and Technology Education 11(1), 29-35. Available from http://journals.sabinet.co.za/Webz/images/ ejour/images/ejour/saarmste/saarmste_v11_n1_a4.pdf?sessionid=01-34166397940713\&format $=F$

Padayachee, P. (2011). A case study: Exploring a DVD driven approach for teaching and learning mathematics, at secondary school level, with a framework of blended learning. Unpublished doctoral dissertation. Nelson Mandela Metropolita University, Port Elizabeth, South Africa. Available from http://www.nmmu.ac.za/ documents/theses/Pragashni\%20Padayachee.pdf

Rossett, A., Douglis, F., \& Frazee, R.V. (2003). Strategies for building blended learning. Retrieved December 12, 2008, from http://www.learningcircuits.org/2003/ jul2003/rossett.htm

Singh, H., \& Reed, C. (2001). Achieving success with blended learning. Retrieved July 11, 2009, from http://notebookmanuals.bestmanualguide.com/a-white-paperachieving-success-with-blended-learning.htm

Valiathan, P. (2002). Blended learning models. Retrieved December 12, 2008, from http://www.astd.org/LC/2002/0802_valiathan.htm

Zenex Foundation. (2007). The Zenex Foundation's ten-year strategy 2006-2015. Retrieved August 22, 2009, from http://www.zenexfoundation.org.za/strategy. php 